\title{
Menkes Disease- A Rare Neurodegenerative Disorder
}

\author{
Choudhary $R^{1}$, Choudhary $A^{2}$, Sitaraman $S^{3}$
}

\begin{abstract}
Menkes Disease is a rare neurological disorder of impaired copper transport, characterized by progressive neurodegeneration, refractory epilepsy and characteristic hair abnormalities. Here, we report a 5 month old child with developmental delay, refractory seizures, and hypopigmented short, sparse hair with microscopic pili torti; low serum copper and ceruloplasmin and neuroimaging revealing white matter hyperintensities and tortuous vessels.
\end{abstract}

Key words: Menkes Disease, Developmental delay, Kinky hair, Refractory seizures, Neurodegenerative disorder

\section{Introduction}

$M$ enkes Disease is a progressive neurodegenerative disorder of copper metabolism with an X-linked recessive inheritance. The predominant clinical manifestations are neurodegeneration and short, sparse, kinky, lightly pigmented hair. Menkes Disease occurs due to mutations in the copper transporting $P$ type ATPase (ATP7A $)^{1}$. We describe a 5 month old infant with Menkes Disease with characteristic clinical features, laboratory investigations and neuroimaging.

\section{The Case}

A five month old male infant was admitted with history of generalized tonic clonic seizures starting at the age of three months. He was second in birth order, born out of a non consanguineous marriage at 38 weeks' gestation by a normal vaginal delivery with an uneventful perinatal period. There was no history of any neonatal complications.The first child of the couple had a similar history of seizures and died at the age of 4 months due to multiple seizures, no records of hospitalization are available. On examination, the infant was lethargic and malnourished. He weighed 5kg (-3SD), head and chest circumference were $39.5 \mathrm{~cm}(-2 S D)$ and $37 \mathrm{~cm}$ respectively; length was $61 \mathrm{cms}(-2 \mathrm{SD})$. The hairs were short, sparse, hypopigmented, wooly and easily pluckable. (Figure 1)

Neurologic examination revealed hypotonia in all four limbs with poor head and trunk support. The deep tendon reflexes were brisk and plantars extensor bilaterally. The development of the infant
'Dr. Richa Choudhary, MBBS, MD, Senior Resident, ${ }^{2}$ Dr. Anita Choudhary, MBBS, MD, DM Paeditric Neurology, Assistant Professor, ${ }^{3}$ Dr. S Sitaraman MBBS, MD, Professor. All from Department of Paediatrics, Sawai Man Singh Medical College, Jaipur, India.

Address for correspondence:

Dr. Richa Choudhary

E-mail: richa_c8@yahoo.co.in

\section{How to cite}

Choudhary R, Choudhary A, Sitaraman S. Menkes Disease- A Rare Neurodegenerative Disorder. J Nepal Paediatr Soc 2015;35(2):176-179.

doi: http://dx.doi.org/10.3126/jnps.v35i2.11966

This work is licensed under a Creative Commons Attribution 3.0 License.

\section{(c) (7)}

was delayed. There was no head control or roll over. Occasional smile and babbling was present. He did not track the objects but blinked in response to light stimulation however fundoscopy was normal. Corneal opacities and iris anomalies were absent. Rest of the systemic examination was unremarkable.

The complete blood counts, liver enzymes, albumin, total protein, blood urea nitrogen and creatinine, serum calcium, phosphorous, alkaline phosphatase, electrolytes, thyroid profile were within normal limits. CSF study was normal. Blood gas analysis, urine ketones, plasma lactate and ammonia levels were normal. Plasma acylcarnitine profile and urine 
gas chromatography-mass spectrometry for organic acidurias were normal. Abdominal ultrasound did not reveal any abnormality. There were no metaphyseal changes in X-rays of limbs. Plasma catecholamine levels and DOPA/DHPG ratio could not be done due to non availability of the tests at our center and financial constraints.

Serum copper was low $14.5 \mu \mathrm{g} / \mathrm{dl}$ (normal range for infants is $20-70 \mu \mathrm{g} / \mathrm{dl}$ ) and serum ceruloplasmin was also low $8.1 \mathrm{mg} / \mathrm{dl}$ (normal 20-60 mg/d). Microscopic analysis of hair showed hypopigmentation and the pathognomonic pili torti i.e. $180^{\circ}$ twisting of the hair shaft. (Figure 2)

Electroencephalogram showed immature background activity with multifocal inter-ictal epileptic discharges. Magnetic resonance imaging showed asymmetric white matter hyperintensities in bilateral frontal and temporal lobes and tortuosity of intracranial flow voids. (Figure 3)
The diagnosis of Menkes Disease was suspected on the basis of typical clinical presentation along with typical hair shaft abnormalities, which was supported biochemically by low levels of serum copper and ceruloplasmin and MRI findings, however diagnostic genetic testing for mutations could not be performed due to non-availability of those tests. Genetic counseling of the parents was done and prognosis was explained. Parenteral copper could not be started due to non availability. Supportive treatment was started. The seizures were controlled on three antiepileptic drugs. The patient was lost to follow up.

\section{Discussion}

Menkes Disease is a genetic disorder of copper metabolism with an $\mathrm{X}$-linked recessive inheritance, first described in $1962^{2}$. It is a rare condition with an incidence of 1 in 298, 000 live births ${ }^{3}$.
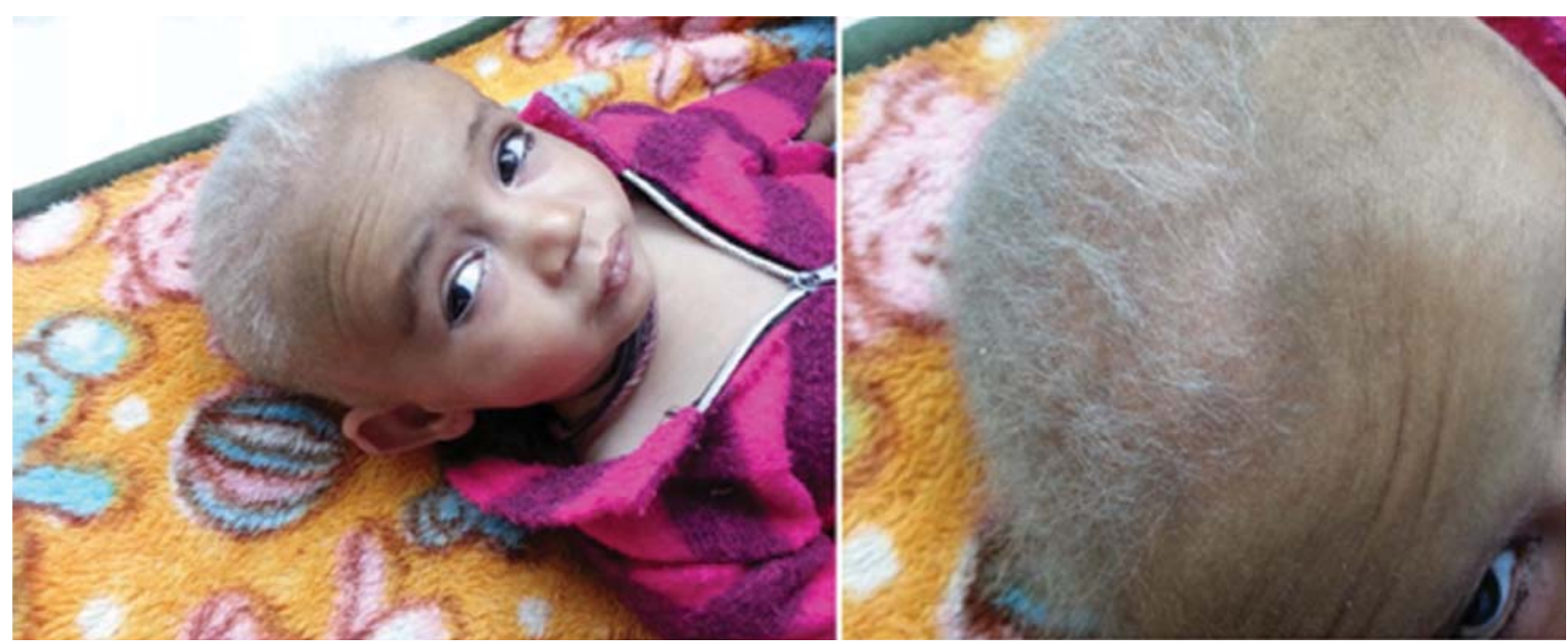

Fig 1: Showing sparse, hypopigmented hair in Menkes Disease
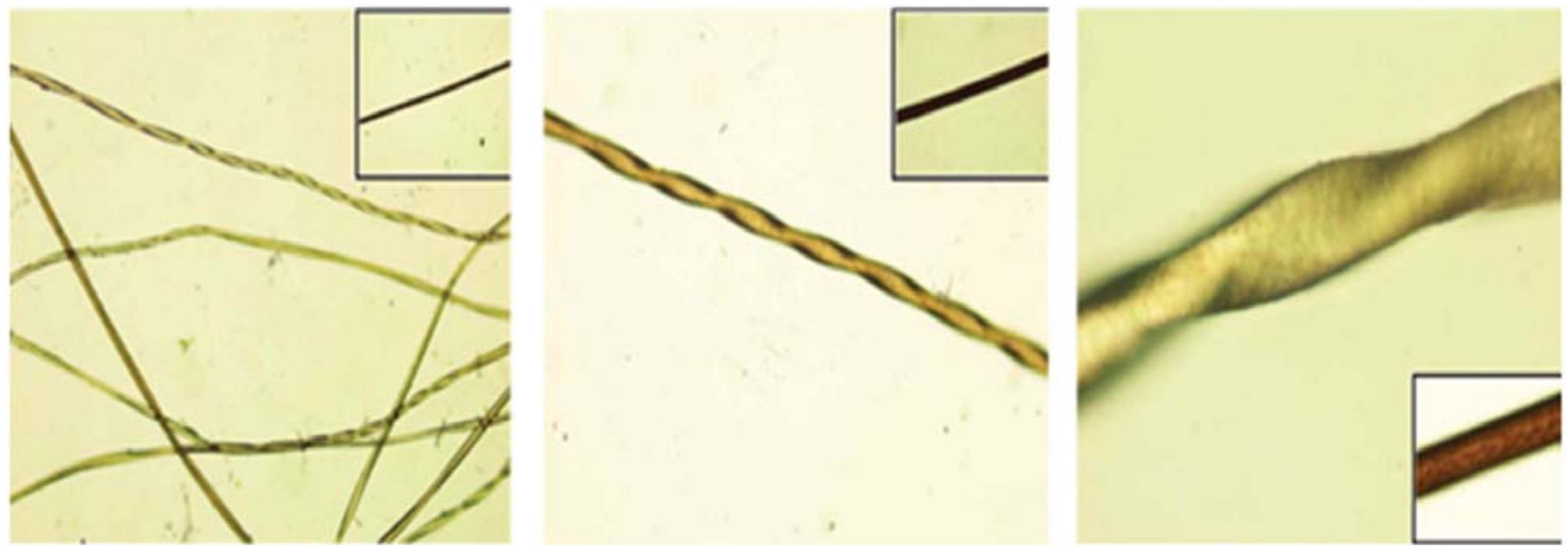

Fig 2: Microscopic examination of hair under magnification $\times 4, \times 10$ and $\times 40$ respectively, showing twisting of hair strands on their own axis- pili torti (compared to normal hair in inset). 


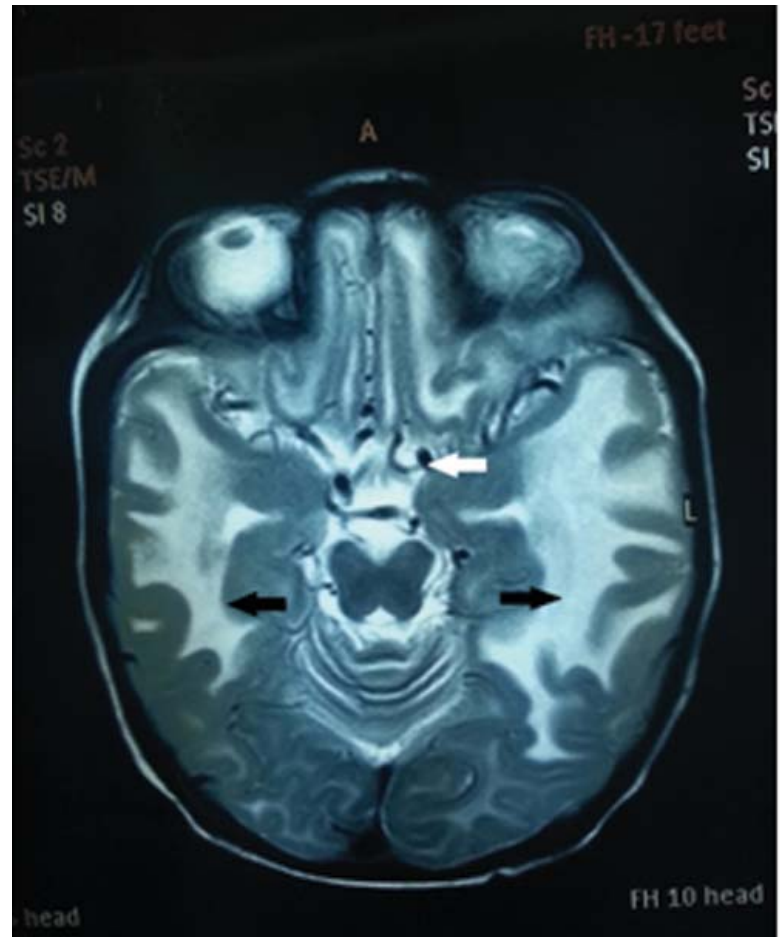

Fig 3: Magnetic Resonance images of the patient: Axial T2-Weighted images showing the hyperintense signal changes of white matter in bilateral temporal lobes(black arrows) and tortuosity of intracranial vascular flow voids (white arrow).

Menkes Disease is caused by mutations in ATP7A gene $^{1}$ encoding a transmembrane protein which is involved in the export of surplus copper from cells and in the delivery of copper to the secreted copper enzymes. Elimination of copper from cells is the basic disturbance in Menkes Disease, resulting in copper accumulation in almost all tissues except liver and brain ${ }^{4}$. Copper is a key cofactor of several enzymes and its deficiency results in malfunction of these cuproenzymes such as cytochrome C oxidase, superoxide-dismutase, tyrosinase and lysyl oxidase, which then leads to a multisystem compromise, especially the central nervous system ${ }^{4}$.

The genetic disorders associated with mutations in the ATP7A gene have variable phenotype and are clinically divided into three categories: classical Menkes Disease, mild Menkes Disease, and Occipital Horn Syndrome (OHS). OHS is considered to be the mildest form.

Menkes disease typically occurs in males with onset at 2-3 mo of age. There is loss of previously obtained developmental milestones, onset of seizures, and failure to thrive. The epileptogenesis in Menkes disease has been attributed to deficits in neurotransmitter function, energy metabolism and excitotoxicity secondary to the copper deficiency in the brain $^{5}$. The characteristic hair findings of short, sparse, depigmented, wooly hair, which on microscopy reveal pili torti, in conjunction with typical neurologic findings, often suggest the initial diagnosis. It is suggested that kinky hair formation results from low activity of sulfhydryl oxidase, a copper enzyme, in hair ${ }^{6}$. Vascular, urogenital and skeletal abnormalities may be seen. Low serum concentration of copper and ceruloplasmin would support the diagnosis further.

The neuroimaging in Menkes Disease typically reveals global atrophy, subdural hygromas, transient temporal lobe abnormalities, excessive tortuosity of cerebral arteries and white matter changes ${ }^{7,8}$. The ultimate diagnostic proof of Menkes Disease is the demonstration of the molecular defect in ATP7A. However, because of the large size of the gene and the variety of the mutations observed in different families, detection of the genetic defect in a given family may take time ${ }^{4}$. Pre-natal diagnosis of Menkes disease is made by gene analysis and measuring copper content in the culture of amniotic liquid cells and chorionic villi ${ }^{9}$.

The current management strategy for Menkes Disease is parenteral copper administration and anticonvulsant therapy. Oral administration of copper is ineffective as copper is trapped in the intestines. Copper histidine normalizes plasma concentrations of copper and ceruloplasmin and reduces epileptic discharges ${ }^{10}$. However, treatment with copperhistidine once neurological symptoms appear is too late to prevent neurodegeneration, possibly because the administered copper accumulates at the bloodbrain barrier and is not transported to neurons ${ }^{11}$. In the natural history of classic Menkes disease, death usually occurs by the age of 2-3 years. Neonatal diagnosis and early treatment with copper injections may enhance survival and improve clinical outcomes in individuals with certain ATP7A mutations ${ }^{12}$.

\section{Conclusion}

We report the case due to its rarity and clinical presentation. The suspicion of Menkes Disease in children with developmental delay and early onset refractory epilepsy is emphasized.

\section{References}

1. Vulpe C, Levinson B, Whitney S, Packman S, Gitschier J. Isolation of a candidate gene for Menkes disease and evidence that it encodes a 
copper-transporting ATPase. Nat Genet 1993; 3(1):7-13.

2. Menkes JH, Alter M, Steigleder GK, Weakley DR, Sung JH. A sex-linked recessive disorder with retardation of growth, peculiar hair and focal cerebral and cerebellar degeneration. Pediatrics 1962;29:764-79.

3. Tonnesen T, Kleijer WJ, Horn N. Incidence of Menkes disease. Hum Genet 1991;86:408-10.

4. Tümer Z, Møller LB. Menkes disease. Eur J Hum Genet 2010;18:511-8.

5. Prasad AN, Levin S, Rupar CA, Prasad C. Menkes disease and infantile epilepsy. Brain Dev 2011;33:866-76.

6. Yamada H, Taneda A, Takamori K, Ogawa H. Menkes' kinky hair disease: Report of a case and distribution of sulfhydryl residues and disulfide bonds in kinky hair. J Eur Acad Dermatol Venereol 1996;6:240-45.

7. Bindu PS, Taly AB, Kothari $S$, Christopher R, Gayathri N, Sinha S, et al. Electro-clinical features and magnetic resonance imaging correlates in Menkes disease. Brain Dev 2013;35(5):398-405.

8. Jain P, Kannan L, Chakrabarty B, Kumar A, Gupta N, Kabra M, Gulati S. Menkes disease - An important cause of early onset refractory seizures. J Pediatr Neurosci $2014 ; 9(1): 11-16$.

9. Gu YU, Kodana H, Sato E, Mochizuki D, Yanagawa $\mathrm{Y}$, Takayanagi $\mathrm{M}$, et al. Prenatal diagnosis of Menkes disease by genetic analysis and copper measurement. Brain Dev 2002;24: 715-8.

10. Christodoulou J, Danks DM, Sarkar B, Baerlocher $\mathrm{KE}$, Casey R, Horn N, et al. Early treatment of Menkes disease with parenteral copper-histidine: long-term follow up of four treated patients. Am J Med Genet 1998;76(2):154-64.

11. Kodama H. Recent developments in Menkes disease. J Inherit Metab Dis 1993;16(4):791-99.

12. Kaler SG, Holmes CS, Goldstein DS, et al. Neonatal diagnosis and treatment of Menkes disease. $N$ Engl J Med 2008;358:605-614. 